\title{
Processes in Engineering via Art
}

\author{
Abraham Tamir* \\ Ben Gurion University of the Negev, Israel
}

Received: July 05, 2017; Published: July 11, 2017

*Corresponding author: Abraham Tamir, Emeritus Professor of Ben Gurion University of the Negev, Beer Sheva, Israel, Email: atamir@012.net.il

\section{Editorial}

Emeritus Professor of Chemical Engineering Department, Ben-Gurion University of the Negev (Israel) Engineering is the application of scientific, economic, social and practical knowledge, in order to build and maintain structures, machines, devices, systems, materials and processes. One who practices engineering is called an engineer. A process is a set of interrelated tasks that, together, transform inputs into outputs. It should be emphasized that the most important step in an engineering process is the design process that is the formulation of a plan to help an engineer build a product with a specified performance goal. This process involves a number of steps, and parts of the process may need to be repeated many times before production of a final product can begin. The combination of process and engineering, namely Process Engineering focuses on the design, operation, control, and optimization of chemical, physical, and biological processes through the aid of systematic computer-based methods. Process engineering encompasses a vast range of industries, such as chemical, petrochemical, mineral processing, advanced material, food, pharmaceutical, and biotechnological industries. The first engineer known by name and achievement was Imhotep, builder of the Pyramid in Egypt, probably in about 2550 BC. The greatest engineering projects man has ever created, that completely changed our perspective over the world are: The Pyramid in Egypt, The Great Wall of China, The Colosseum in Rome, Italy, The Taj Mahal in Agra, India, The Trans-Siberian Railway, Russia, The Panama Canal, The Hoover Dam in Arizona/Nevada, USA, The Burj Khalifa in Dubai, UAE, The Channel Tunnel, France/England, The Kansai Airport in Osaka, Japan, The Palm Islands in Dubai, UAE and The Qingdao Haiwan Bridge in Qingdao, China. In the following different engineering processes will be described by artworks. Figure 1 demonstrates a refinery in which a refining process is performed. An oil refinery or petroleum refinery is an industrial process plant where crude oil is processed and refined into more useful products such as petroleum naphtha, gasoline, diesel fuel, and asphalt base, heating oil, kerosene, and liquefied petroleum gas. (Figure 2) is a surrealistic demonstration of the combustion process that is the chemical reaction of a particular substance with an oxidant that is accompanied by the production of heat and conversion of chemical species. (Figure 3) demonstrates the evaporation process defined as the process by which liquid water is converted into a gaseous state. On the other hand (Figure 4) is the demonstration of the condensation process that is the change of the matter from gaseous state into liquid state. (Figure 4) demonstrated a condensed phase formed by the condensation process that is the change of the matter from gaseous state into liquid state. (Figure 5) demonstrates the common way of fluid flow where (Figure 6) presents the old water pump to create the process of fluid flow. (Figure 7) demonstrates a crystal formed by crystallization that is a process by which a chemical is converted from a liquid solution into a solid crystalline state. (Figure 8) demonstrates the process of doing work where work is the measure of a quantity that is capable of accomplishing macroscopic motion of a system due to the action of a force over a distance. Here the system is the dancing couple. (Figure 9) demonstrates the process of drying by a towel that is a piece of absorbent fabric used for drying or wiping. Drying is defined as a mass transfer process consisting of the removal of water or another solvent from a wet body. (Figure 10) demonstrates the process of mass transfer defined as the net movement of mass from one location to another. (Figure 11) demonstrates the process of heat transfer that is the energy in transit due to temperature difference. (Figure 12) demonstrates the cooling process by a picture of Global cooling. Cooling process is defined as the operation in which heat is removed from a system by evaporation of liquids, expansion of gases, radiation or heat exchange to a cooler fluid stream, and so on. And finally (Figure 13) demonstrates the process of radiation that is energy coming from a source and travels through some material or through space. In conclusion the authors believe that the artistic demonstration of the different engineering processes makes them clearer and easy to perception.

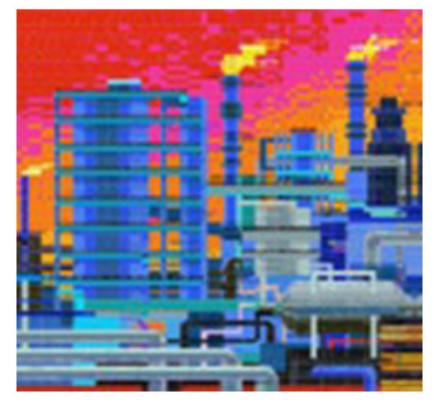

Figure 1: Demonstration of a refinery. 


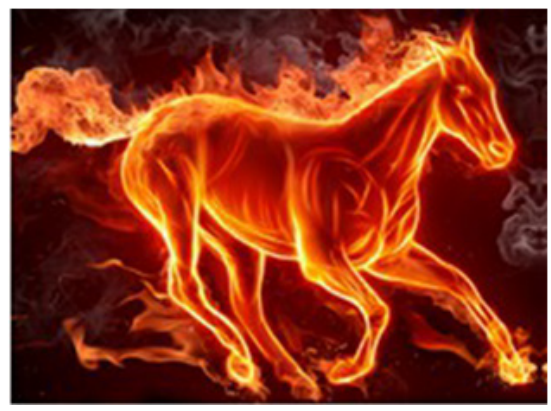

Figure 2: Surrealistic demonstration of the combustion process.

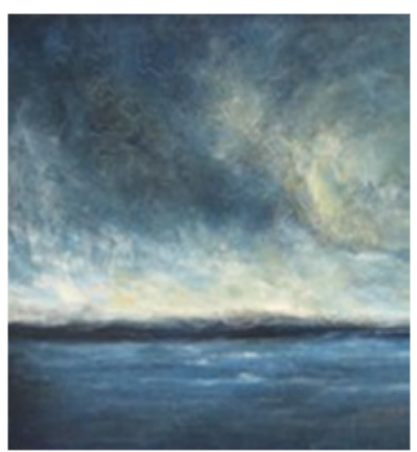

Figure 3: Evaporation process.

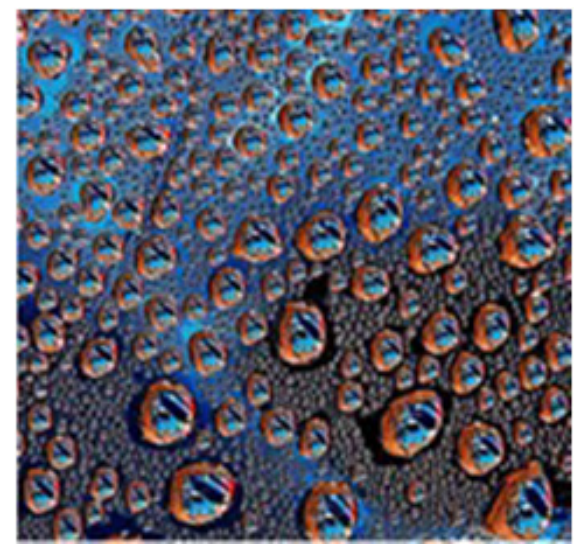

Figure 4: Condensation process.

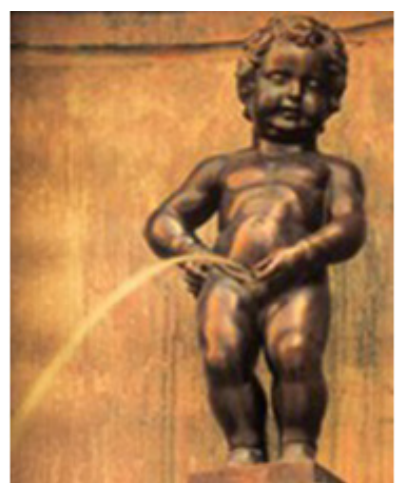

Figure 5: Common way of fluid flow.
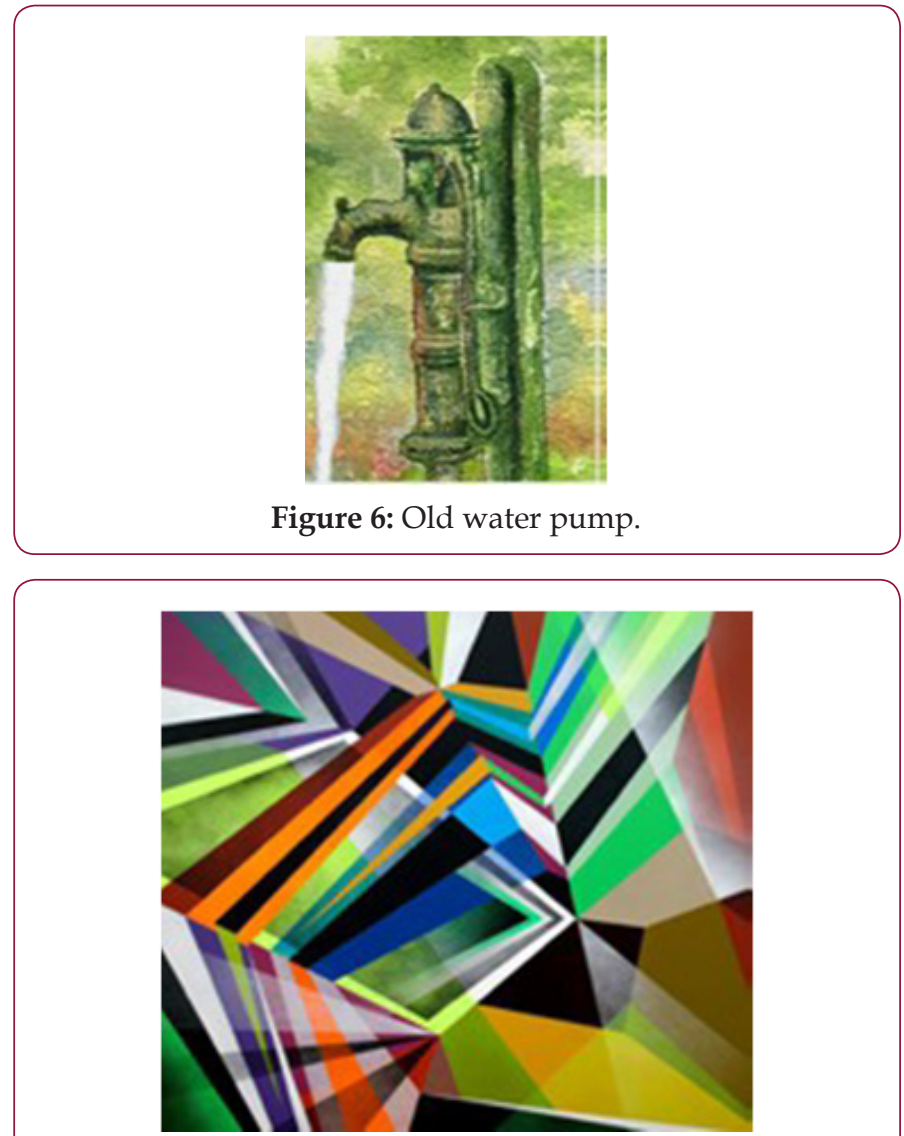

Figure 7: Crystal formed by crystallization.

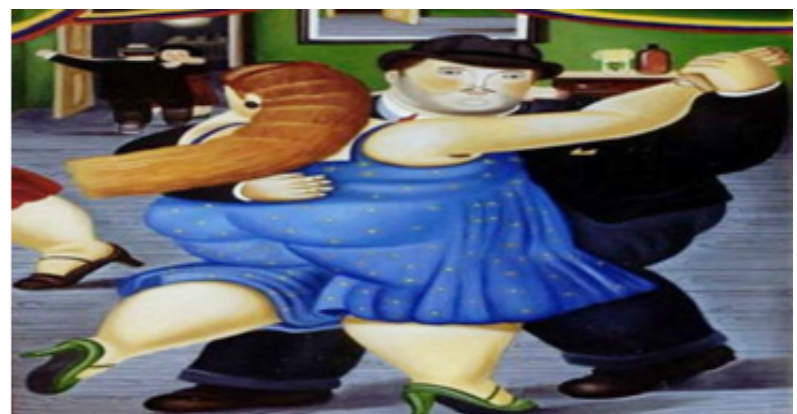

Figure 8: Process of doing work.

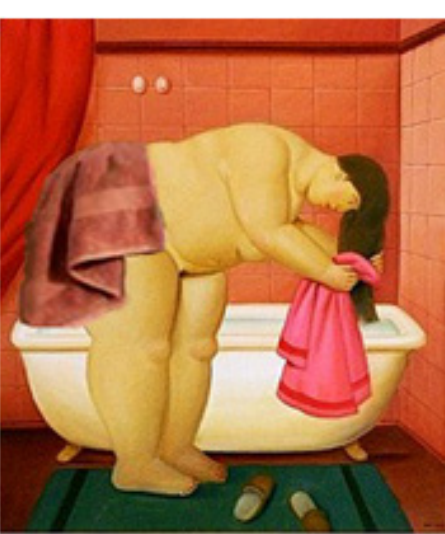

Figure 9: Process of drying. 

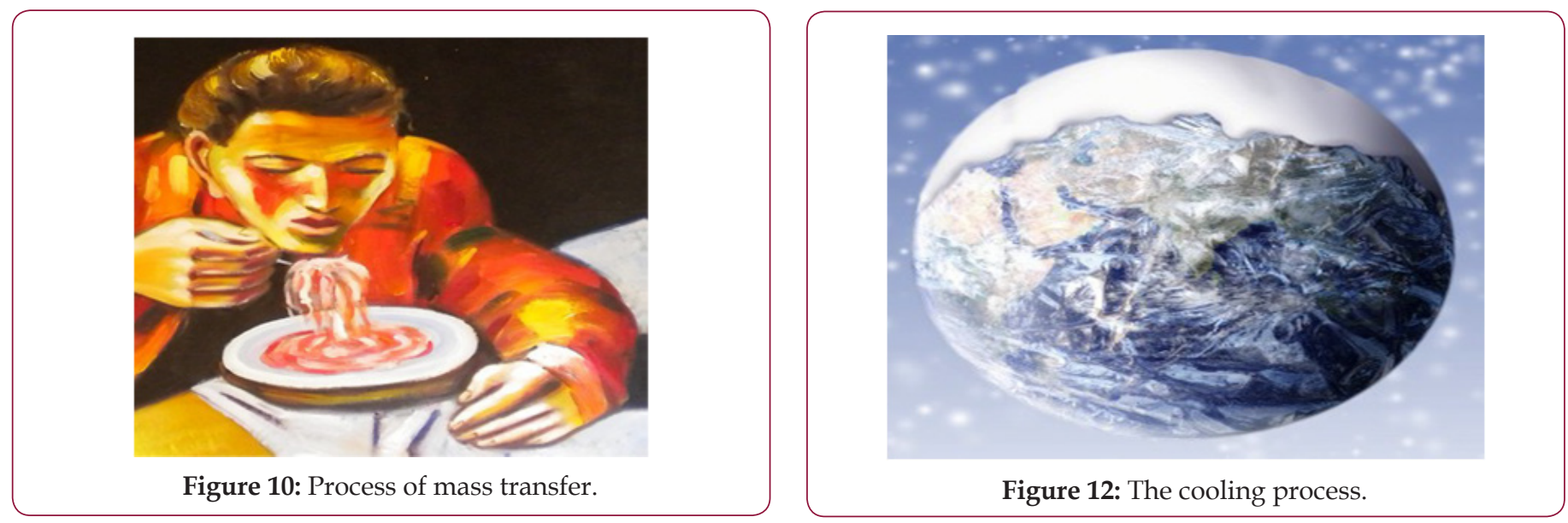

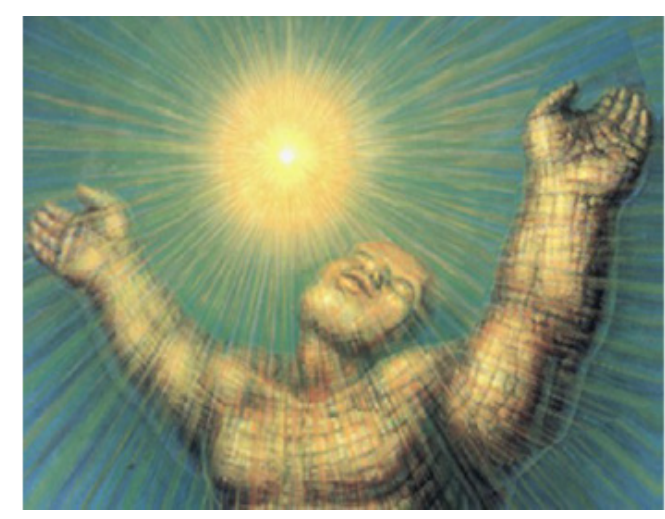

Figure 11: Process of heat transfer.

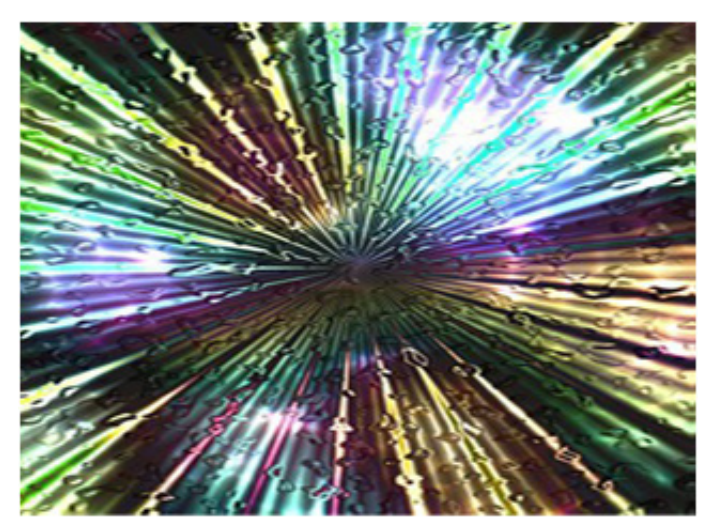

Figure 13: The process of radiation.

$\begin{array}{ll}\text { BIOMEDICAL } & \begin{array}{l}\text { Assets of Publishing with us } \\ \text { - GeSERCHES }\end{array} \\ \text { - Immediate, unrestricted online access }\end{array}$

